\title{
Self-Efficacy, Learner Satisfaction, and Associated Factors of Simulation Based Education among Midwifery Students: A Cross-Sectional Study
}

\author{
Temesgen Worku Gudayu, Marta Berta Badi, and Mengstu Melkamu Asaye \\ Department of Midwifery, College of Medicine and Health Sciences, University of Gondar, Gondar, P.O. Box 196, Ethiopia \\ Correspondence should be addressed to Temesgen Worku Gudayu; teme.worku@gmail.com
}

Received 26 August 2015; Revised 1 December 2015; Accepted 2 December 2015

Academic Editor: Shu-Sheng Liaw

Copyright (c) 2015 Temesgen Worku Gudayu et al. This is an open access article distributed under the Creative Commons Attribution License, which permits unrestricted use, distribution, and reproduction in any medium, provided the original work is properly cited.

\begin{abstract}
Introduction. Midwifery training needs intensive skill practice. Simulation based teaching is found to be a good alternative to fill skill teaching gaps and to safeguard human patients. Objective. To assess self-efficacy, learner satisfaction, and associated factors of simulation based education among Midwifery students in Gondar University, 2015. Methods. Cross-sectional study was conducted among Midwifery students. A total of 144 students participated in the study. SPSS version 20 statistical software was used for analysis. Binary and multivariable logistic regression analysis were done to assess associations of explanatory variables with outcome variables. Finally the strength of association was determined by adjusted odds ratio with $95 \%$ confidence interval and $p$ value $<0.05$. Result. In this study the proportion of satisfaction and confidence in simulation learning was $54.2 \%$ and $50.7 \%$ among participants, respectively. Students who perceived instructors' assistance during skill practice as "good" showed statistically significant satisfaction, while those students who were satisfied and perceived instructors' assistance as "good" showed statistically significant confidence during skill practice. Conclusion and Recommendation. levels of satisfaction and self-efficacy of simulation based teaching among Midwifery students are low. Designing a mechanism to improve instructors' assistance at simulation based teaching is recommended.
\end{abstract}

\section{Background}

Midwifery is a science that is much an art in its nature [1]. Development of psychomotor technical skills is critical for safe Midwifery practice [2]. Since Midwifery profession is involved in clinical judgments that have direct effect on mother and fetal health [3], it is necessary for Midwifery students to be skillful at the highest level before entering into the health care system [4].

Studies showed that most newly graduated health professionals do not have the required skills to perform psychomotor procedures [5]. One of the causes for this can be difficulty in finding a safe clinical environment to provide good clinical experiences for students during the limited time of education [6]. In fact, this is more prevalent in our setup, due to the fact that there is large number of students practicing in small sized hospital wards.
In practice-based health care education, like Midwifery and Nursing, methods of teaching and learning should focus on enabling students to assimilate clinical knowledge and skills. Such students need to learn how to apply class room education in the clinical context. Human simulation may well be an educational strategy for achievement of these outcomes, since it uses active learning [7].

Human simulation aims to imitate reality whilst offering skills-based clinical experience in a safe and secure environment [8]. Hovancsek describes the aim of simulation as "to replicate some or nearly all of the essential aspects of a clinical situation so that the situation may be more readily understood and managed when it occurs for real in clinical practice" [9]. Furthermore, key aspects of simulation education are the ability to repeat practice to consolidate learning and develop competence [10-12], using instructor feedback and video debriefing $[13,14]$. 
Kneebone [15] suggests that simulation may be an effective method of learning because it implicates four key facets of education in Midwifery and Nursing: developing technical proficiency through practice of psychomotor skills and repetition; assistance of experts which is tailored to students' needs; situated learning within context; and incorporation of the affective (emotional) component of learning.

In studies among undergraduate students, greater levels of confidence with low- or medium-fidelity simulation was shown [16, 17]. There were also favorable results when simulation was used in the continuing education of health care professionals [18]. It is found that teams who were taught by simulation alone were the only group to demonstrate longterm improvement in obstetric emergency skills and they experienced less anxiety in subsequent emergencies.

Research by Gordon and Buckley [19] explored that simulation based teaching on medical-surgical graduate nurses' resulted in confidence and perceived ability to respond in clinical emergencies. Other studies $[20,21]$ also reported that simulation design, clear learning objectives, and an appropriately challenging problem were all significantly correlated with students' satisfaction and self-confidence.

Thus this current study aimed to assess self-efficacy, learner satisfaction, and associated factors of simulation based education among Midwifery students in our setup. Because of limited studies in this area in general at the country level, the findings will create new insight for further research and necessitate instructional designing.

\section{Methods}

\subsection{Study Design. Cross-sectional study was employed.}

2.2. Study Area and Period. The study was conducted from May 1 to 15, 2015, in Department of Midwifery, University of Gondar, North Gondar zone, $741 \mathrm{Km}$ North West to Addis Ababa the capital of Ethiopia.

The department is currently enrolling over 700 students in both undergraduate and postgraduate programs. Besides class room teaching, the department is utilizing university of Gondar Referral Hospital, health centers in the town, and simulation laboratories for skill practice.

\subsection{Population}

2.3.1. Source Population. Source population is all baccalaureate Midwifery students studying at University of Gondar Department of Midwifery.

2.3.2. Study Population. All baccalaureate Midwifery students who attended at least one clinical attachment for skill practice.

2.3.3. Inclusion and Exclusion Criteria. All eligible sampled students were included in the study.

2.4. Sample Size Determination. A sample size was obtained using a single population proportion formula to estimate sample size for cross-sectional study based on the following assumptions:

$$
n=\frac{Z_{\alpha / 2}^{2} p(1-p)}{w^{2}}
$$

$n$ is required minimum sample size for single population, $Z_{\alpha / 2}=1.96$ at $95 \%$ level of confidence, $p=50 \%$, and $w=5 \%$ margin of error. Since total study population was 231 students, considering correction formula and 5\% nonresponse rate, final sample size became 152 .

2.5. Sampling Technique. Simple random sampling technique was used.

\subsection{Variables of Study}

2.6.1. Outcome Variable. Learners' self-efficacy and satisfaction on simulation based learning.

2.6.2. Explanatory Variables. Explanatory variables are sociodemographic variables, student's academic performance, students' English language proficiency, teacher's related factors, simulation lab infrastructure, and materials related variables.

\subsection{Operational Definition}

2.7.1. Self-Efficacy. The theoretical definition of self-efficacy in this study is the "conviction that one can successfully execute the behavior required to produce the outcomes" [20]. Bandura believed that personal accomplishment and motivation are based on the foundation of self-efficacy and that selfefficacy changes over time as new knowledge and skills are acquired. As self-efficacy increases, self-confidence increases. He theorized that a student's self-efficacy played a significant role in his/her successes and failures in school. Based on these principles of self-efficacy, nursing students who have high perceptions of self-efficacy should feel confident in their ability to learn and develop clinical judgment skills. Therefore, for the purposes of this study, the operational definition of self-efficacy is student perceptions of confidence in one's ability to learn and perform clinical skills in a simulation clinical experience. And students who score a mean value and above for self-confidence questions were considered as confident.

2.7.2. Learner Satisfaction. Learner satisfaction is the degree to which the learners believe that the learning experience meets their learning needs. Satisfied learners value their learning experience and will put more effort into their performance [21].

Five-scale Likert survey questions which were adopted from National League for Nursing [22] were used and satisfaction and self-efficacy were categorized based on the mean value. 
2.7.3. Simulation. Simulation is "activities that mimic reality and variously involve role-playing, interactive videos, or mannequins that help students learn and allow them to demonstrate decision making, critical thinking and other skills" [23].

\subsubsection{English Language Competency}

Perceived Good Competency. This indicates general professional proficiency, ability to speak the language with sufficient structural accuracy and vocabulary to participate effectively in most formal and informal conversations and ability to read within a normal range of speed and with almost complete comprehension.

Perceived Less Competency. This indicates limited working proficiency, speaking to satisfy routine social demands and limited work requirements and having sufficient comprehension to read simple and authentic written material in a form equivalent to usual printing or typescript on familiar subjects.

Perceived Level of Teacher's Assistance on Skill Teaching. It is the level of students' perception on teachers' assistance during simulation based skills teaching as "good" or "not good."

2.8. Data Collection Procedure. Structured and pretested questionnaire on sociodemographic variables, academic performance, simulation teaching experience, self-efficacy, and satisfaction related variables which was adopted from National League for Nursing [22] was used for data collection. Then data was collected through self-administered questionnaire.

2.9. Data Management and Quality Control Measures. Data collection tool was pretested for consistency of responses by taking $5 \%$ of the sample size among Midwifery students who did not participate in the study and the necessary amendment was done. Then orientation on the details of data collection tool was given for participants and they were given time to respond to each question as per the orientation.

2.10. Data Processing and Analysis. All collected questionnaires were checked for completeness and consistency of responses manually. Then data was coded and entered into EPI INFO version 3.5.3 and analyzed using SPSS for Windows version 20.0. Univariate and multivariate analysis were done. Descriptive statistics were presented in frequency tables. Logistic regression model was used to identify association between the dependent and independent variables.

2.11. Ethical Consideration. Ethical clearance was obtained from the Ethical Committee of Department of Midwifery. The department officials were communicated through formal letter to get permission for data collection. Participants were informed about the purpose and objective of the study. They were informed that they have the right to discontinue or refuse to participate in the study. Verbal consent was
TABLE 1: Demographic characteristics of Midwifery students in Gondar University, 2015.

\begin{tabular}{lcc}
\hline Variables & Frequency & Percent \\
\hline Sex & 77 & \\
$\quad$ Male & 67 & 43.5 \\
$\quad$ Female & & \\
Age & 138 & 95.8 \\
$\quad<25$ & 6 & 4.2 \\
$\quad \geq 25$ & & \\
Level of study & 46 & 31.9 \\
$\quad$ th year regular program & 69 & 48.0 \\
$\quad$ 3rd year regular program & 29 & 20.1 \\
$\quad$ 4th year extension (weekend) program & & \\
English language competency & 93 & 64.6 \\
$\quad$ Perceived good competency & 51 & 35.4 \\
$\quad$ Perceived less competency & & \\
Cumulative grade point average (CGPA) & & \\
$\quad \geq 3.29$ (mean value) & 86 & 59.7 \\
$\quad<3.29$ (mean value) & 58 & 40.3 \\
\hline
\end{tabular}

$n=144$.

obtained from each study participant and confidentiality of information and privacy were maintained.

\section{Result}

3.1. Demographic Characteristics of Study Participants. A total of 144 students participated in the study making a response rate $94.74 \%$. Among participants in this study $53.5 \%$ were males and nearly $96 \%$ were younger than 25 years. About half of participants were third year students and the rest were in their graduating class. Almost $60 \%$ of participants in this study had a cumulative grade point average of greater than and equal to mean value (Table 1).

3.2. Levels of Satisfaction and Self-Confidence. More than half of the participants showed an aggregate of "agree and strongly agree" levels for most items of satisfaction and selfconfidence (Table 2). The proportion of (mean and above) satisfaction and self-confidence in this study was $54.2 \%$ and $50.7 \%$, respectively.

To check for the internal consistency of the 14-item satisfaction and self-confidence measurement tool, we did reliability analysis. The overall Cronbach's alpha value was 0.861 and that of satisfaction and self-confidence separately was 0.772 and 0.812 , respectively, reflecting a very high consistency of instrument to measure satisfaction and selfconfidence.

3.3. Determinants of Satisfaction and Self-Confidence. Multivariable logistic regression analysis showed that students who perceived the level of teachers' assistance as "good" were satisfied on simulation teaching compared to their counterparts (Table 3). On the other hand students who 
TABLE 2: Levels of satisfaction and self-confidence of Midwifery students in simulation based teaching at Gondar University, 2015.

\begin{tabular}{|c|c|c|c|c|c|}
\hline \multirow{2}{*}{ Items } & \multicolumn{5}{|c|}{ Satisfaction } \\
\hline & Strongly disagree & Disagree & Undecided & Agree & Strongly agree \\
\hline $\begin{array}{l}\text { The teaching methods used in this simulation } \\
\text { were helpful and effective. }\end{array}$ & $11(7.6 \%)$ & $20(13.9 \%)$ & $17(11.8 \%)$ & $78(54.2 \%)$ & $18(12.5 \%)$ \\
\hline $\begin{array}{l}\text { The simulation provided me with a variety of } \\
\text { learning materials and activities to promote my } \\
\text { learning the medical surgical curriculum. }\end{array}$ & $9(6.3 \%)$ & $24(16.7 \%)$ & $23(16.0 \%)$ & $73(50.7 \%)$ & $15(10.4 \%)$ \\
\hline $\begin{array}{l}\text { I enjoyed how my instructor taught the } \\
\text { simulation. }\end{array}$ & $13(9.0 \%)$ & $39(27.1 \%)$ & $31(21.5 \%)$ & $55(38.2 \%)$ & $6(4.2 \%)$ \\
\hline $\begin{array}{l}\text { The teaching materials used in this simulation } \\
\text { were motivating and helped me to learn. }\end{array}$ & $12(8.3 \%)$ & $22(15.3 \%)$ & $18(12.5 \%)$ & $76(52.8 \%)$ & $16(11.1 \%)$ \\
\hline $\begin{array}{l}\text { The way my instructor(s) taught the simulation } \\
\text { was suitable to the way I learn. }\end{array}$ & $14(9.7 \%)$ & $34(23.6 \%)$ & $22(15.3 \%)$ & $65(45.1 \%)$ & $9(6.3 \%)$ \\
\hline Self-confidence in learning & Strongly disagree & Disagree & Undecided & Agree & Strongly agree \\
\hline $\begin{array}{l}\text { I am confident that I am mastering the content of } \\
\text { the simulation activity that my instructors } \\
\text { presented to me. }\end{array}$ & $14(9.7 \%)$ & $26(18.1 \%)$ & $29(20.1 \%)$ & $62(43.1 \%)$ & $13(9.0 \%)$ \\
\hline $\begin{array}{l}\text { I am confident that this simulation covered } \\
\text { critical content necessary for the mastery of } \\
\text { medical surgical curriculum. }\end{array}$ & $11(7.6 \%)$ & $28(19.4 \%)$ & $22(15.3 \%)$ & $66(45.8 \%)$ & 17 (11.8\%) \\
\hline $\begin{array}{l}\text { I am confident that I am developing the skills and } \\
\text { obtaining the required knowledge from this } \\
\text { simulation to perform necessary tasks in a clinical. }\end{array}$ & $12(8.3 \%)$ & $32(22.2 \%)$ & $29(20.1 \%)$ & $57(39.6 \%)$ & $14(9.7 \%)$ \\
\hline $\begin{array}{l}\text { I became confident in my clinical activities of 1st } \\
\text { semester because of the simulation I practiced } \\
\text { before. }\end{array}$ & $13(9.0 \%)$ & $33(22.9 \%)$ & $27(18.8 \%)$ & $58(40.3 \%)$ & $13(9.0 \%)$ \\
\hline $\begin{array}{l}\text { My instructors used helpful resources to teach the } \\
\text { simulation. }\end{array}$ & $16(11.1 \%)$ & $48(33.3 \%)$ & $25(17.4 \%)$ & $45(31.3 \%)$ & $10(6.9 \%)$ \\
\hline $\begin{array}{l}\text { It is my responsibility as the student to learn what } \\
\text { I need to know from this simulation activity. }\end{array}$ & $5(3.5 \%)$ & $9(6.3 \%)$ & $15(10.4 \%)$ & $73(50.7 \%)$ & $42(29.2 \%)$ \\
\hline $\begin{array}{l}\text { I know how to get help when I do not understand } \\
\text { the concepts covered in the simulation. }\end{array}$ & $9(6.3 \%)$ & $13(9.0 \%)$ & $25(17.4 \%)$ & $75(52.1 \%)$ & $22(15.3 \%)$ \\
\hline $\begin{array}{l}\text { I know how to use simulation activities to learn } \\
\text { critical aspects of these skills. }\end{array}$ & $9(6.3 \%)$ & $14(9.7 \%)$ & $29(20.1 \%)$ & $76(52.8 \%)$ & $16(11.1 \%)$ \\
\hline $\begin{array}{l}\text { It is the instructor's responsibility to tell me what I } \\
\text { need to learn of the simulation activity content } \\
\text { during class time. }\end{array}$ & $23(16.0 \%)$ & $30(20.8 \%)$ & $18(12.5 \%)$ & $52(36.1 \%)$ & $21(14.6 \%)$ \\
\hline
\end{tabular}

$n=144$.

had a good perception on the level of teachers' assistance and those who were satisfied on simulation based teaching showed statistically significant level of self-confidence (Table 4).

\section{Discussion}

Skills learning experiences such as simulation teaching help to prepare students for the realities of the health care field. In Midwifery education, simulation is an educational strategy that has the potential to engage learners in realistic learning environments where they can practice skills and care for patients without being overly concerned about harming the patients [24].

The purpose of this study was to evaluate the use of simulation to impact the development of clinical self-efficacy in Midwifery students. It also evaluated students' satisfaction with simulation as an education strategy.

In this study, about half of the participants were satisfied in simulation based teaching and had developed self-confidence in skill practicing. Simulator manikins promote science, critical thinking, and students' satisfaction with education [25]. It is revealed that, besides attending skills teaching, the higher level of students' participation during skills practice showed high degree of satisfaction [26].

Simulation teaching is found to lead students to satisfaction and self-confidence [27]. Students who are self-confident have a significant opportunity to understand and become successful in their clinical practices [28].

The current study revealed that students who perceived that teachers assistance during skill teaching was good showed statistically significant association with satisfaction. 
TABLE 3: Logistic regression analysis of variables with satisfaction on simulation based teaching.

\begin{tabular}{|c|c|c|c|c|}
\hline \multirow{2}{*}{ Variables } & \multicolumn{2}{|c|}{ Satisfaction on simulation teaching } & \multirow{2}{*}{ COR $(95 \% \mathrm{CI})$} & \multirow{2}{*}{$\operatorname{AOR}(95 \% \mathrm{CI})$} \\
\hline & Satisfied & Less satisfied & & \\
\hline \multicolumn{5}{|l|}{ Year of study } \\
\hline 4th year regular & $33(71.7 \%)$ & $13(28.3 \%)$ & $2.769(1.248,6.144)$ & $2.362(0.995,5.605)$ \\
\hline 4 th year extension & $12(41.4 \%)$ & $17(58.6 \%)$ & $0.770(0.320,1.851)$ & $0.697(0.269,1.810)$ \\
\hline 3 rd year regular & $33(47.8 \%)$ & $36(52.2 \%)$ & 1 & 1 \\
\hline \multicolumn{5}{|l|}{ Profession selection } \\
\hline 1st choice & $63(60.0 \%)$ & $42(40.0 \%)$ & $3.214(1.208,8.551)$ & $* * *$ \\
\hline Was not 1st choice & $8(47.1 \%)$ & $9(52.9 \%)$ & $1.905(0.515,7.048)$ & $* * *$ \\
\hline Do not have interest on this profession & $7(31.8 \%)$ & $15(68.2 \%)$ & 1 & \\
\hline \multicolumn{5}{|l|}{ Skill practicing per semester } \\
\hline$\geq 2$ practices & $44(60.3 \%)$ & $29(39.7 \%)$ & $1.651(0.853,3.197)$ & $* * *$ \\
\hline$<2$ practices & $34(47.9 \%)$ & $37(52.1 \%)$ & 1 & \\
\hline \multicolumn{5}{|l|}{$\begin{array}{l}\text { Perceived level of teacher's assistance on skill } \\
\text { teaching }\end{array}$} \\
\hline Good & $65(69.1 \%)$ & $29(30.9 \%)$ & $6.379(2.958,13.76)$ & $6.043(2.751,13.27)^{* *}$ \\
\hline Not good & $13(26.0 \%)$ & $37(74.0 \%)$ & 1 & 1 \\
\hline
\end{tabular}

${ }^{* *} p$ value $<0.001 ;{ }^{* * *}$ variables did not show statistically significant association.

$n=144$.

TABLE 4: Logistic regression analysis of variables with satisfaction on simulation based teaching.

\begin{tabular}{|c|c|c|c|c|}
\hline \multirow{2}{*}{ Variables } & \multicolumn{2}{|c|}{ Self-confidence on simulation teaching } & \multirow{2}{*}{ COR (95\% CI) } & \multirow{2}{*}{ AOR (95\% CI) } \\
\hline & Confident & Less confident & & \\
\hline \multicolumn{5}{|l|}{ Profession selection } \\
\hline 1st choice & $58(55.2 \%)$ & $47(44.8 \%)$ & $2.644(0.996,7.019)$ & $* * *$ \\
\hline Was not 1st choice & $8(47.1 \%)$ & $9(52.9 \%)$ & $1.905(0.515,7.048)$ & $* * *$ \\
\hline Do not have interest & $7(31.8 \%)$ & $15(68.2 \%)$ & 1 & \\
\hline \multicolumn{5}{|l|}{ Skill practicing/semester } \\
\hline$<2$ practices & $30(42.3 \%)$ & $41(57.7 \%)$ & 1 & \\
\hline$\geq 2$ practices & $43(58.9 \%)$ & $30(41.1 \%)$ & $1.959(1.010,3.800)$ & $* * *$ \\
\hline \multicolumn{5}{|c|}{$\begin{array}{l}\text { Perceived level of teacher's assistance on skill } \\
\text { teaching }\end{array}$} \\
\hline Good & $60(63.8 \%)$ & $34(36.2 \%)$ & $5.023(2.351,10.73)^{* *}$ & $2.897(1.255,6.687)$ \\
\hline Not good & $13(26.0 \%)$ & $37(74.0 \%)$ & 1 & 1 \\
\hline \multicolumn{5}{|c|}{ Satisfaction on simulation teaching } \\
\hline Less satisfied & $17(25.8 \%)$ & $49(74.2 \%)$ & 1 & 1 \\
\hline Satisfied & $56(71.8 \%)$ & $22(28.2 \%)$ & $7.337(3.501,15.38)^{* *}$ & $5.31(2.434,11.58)^{* *}$ \\
\hline
\end{tabular}

It is a fact that closely assisted students can show satisfaction in simulation based teaching. As reported in previous studies, simulation based teaching promotes students' satisfaction [25] and teachers assistance further impacts learning clinical skills [29].

On the other hand students who were satisfied and perceived teacher's assistance as "good" were self-confident in simulation based teaching. A number of studies showed significant increase in self-confidence among study groups trained through simulation methods [30-33]. From this we can extrapolate that teacher's assistance could satisfy and increase students' self-confidence not only in simulation but also in actual patient care.

\section{Conclusion and Recommendation}

Levels of satisfaction and self-efficacy of simulation based teaching among Midwifery students are low compared to previous studies. Designing a mechanism to improve instructors' assistance at simulation based teaching is recommended.

\section{Conflict of Interests}

The authors have declared that they have no competing interests. 


\section{Authors' Contribution}

All three authors designed the study, participated in the data collection, performed analysis and interpretation of data, drafted the paper, and developed and revised the paper. All authors contributed equally to this work.

\section{Acknowledgments}

The authors are highly indebted to Department of Midwifery, College of Medicine \& Health Sciences, University of Gondar, for providing ethical clearance. The authors would like to extend their thanks to Nursing Education Partner Initiative (NEPI) Program in Ethiopia for providing financial support to conduct the study. They would also like to extend their appreciation to the study participants, supervisors, and data collectors.

\section{References}

[1] D. M. Dole and C. F. Nypaver, "Nurse-midwifery: art and science," Nursing Clinics of North America, vol. 47, no. 2, pp. 205213, 2012.

[2] J. T. Fullerton, A. Ghérissi, P. G. Johnson, and J. B. Thompson, "Competence and competency: core concepts for international midwifery practice," International Journal of Childbirth, vol. 1, no. 1, pp. 4-12, 2011.

[3] F. Rahimikian, T. Mirmolaei, Z. Samizadeh, M. Shirazi, and A. Mehran, "Evaluation of knowledge and practice of newly graduated midwives in normal vaginal delivery in hospitals affiliated to Tehran University of Medical Sciences," Iranian Journal of Medical Education, vol. 7, no. 1, pp. 51-57, 2007.

[4] M. Delaram, "Clinical education from the viewpoints of nursing and midwifery students in Shahrekord University of Medical Sciences," Iranian Journal of Medical Education, vol. 6, no. 2, pp. 129-132, 2006.

[5] V. L. Salyers, “Teaching psychomotor skills to beginning nursing students using a web-enhanced approach: a quasiexperimental study," International Journal of Nursing Education Scholarship, vol. 4, article 11, 2007.

[6] M. W. Bultas, "Enhancing the pediatric undergraduate nursing curriculum through simulation," Journal of Pediatric Nursing, vol. 26, no. 3, pp. 224-229, 2011.

[7] J. Cioffi, "A study of the use of past experiences in clinical decision making in emergency situations," International Journal of Nursing Studies, vol. 38, no. 5, pp. 591-599, 2001.

[8] C. Fowler-Durham and K. Alden, "Enhancing patient safety in nursing education through patient simulation," in Patient Safety and Quality: An Evidence-Based Handbook for Nurses, R. G. Hughes, Ed., US Department of Health and Human Services, Agency for Healthcare Research and Quality, Rockville, Md, USA, 2007.

[9] M. Hovancsek, "Using simulation in nurse education," in Simulation in Nursing Education; From Conceptualization to Evaluation, P. R. Jeffries, Ed., pp. 1-9, National League for Nursing, New York, NY, USA, 2007.

[10] S. B. Issenberg, W. C. McGaghie, E. R. Petrusa, D. L. Gordon, and R. J. Scalese, "Features and uses of high-fidelity medical simulations that lead to effective learning: a BEME systematic review," Medical Teacher, vol. 27, no. 1, pp. 10-28, 2005.
[11] G. Hogg, E. S. Pirie, and J. Ker, “The use of simulated learning to promote safe blood transfusion practice," Nurse Education in Practice, vol. 6, no. 4, pp. 214-223, 2006.

[12] S. E. Kardong-Edgren, A. R. Starkweather, and L. D. Ward, "The integration of simulation into a clinical foundations of nursing course: student and faculty perspectives," International Journal of Nursing Education Scholarship, vol. 5, no. 1, 2008.

[13] R. M. Fanning and D. M. Gaba, "The role of debriefing in simulation-based learning," Simulation in Healthcare, vol. 2, no. 2, pp. 115-125, 2007.

[14] R. Kuiper, C. Heinrich, A. Matthias, M. J. Graham, and L. BellKotwall, "Debriefing with the OPT model of clinical reasoning during high fidelity patient simulation," International Journal of Nursing Education Scholarship, vol. 5, article 17, 2008.

[15] R. Kneebone, "Evaluating clinical simulations for learning procedural skills: a theory-based approach," Academic Medicine, vol. 80, no. 6, pp. 549-553, 2005.

[16] D. Bambini, J. Washburn, and R. Perkins, "Outcomes of clinical simulation for novice nursing students: communication, confidence, clinical judgment," Nursing Education Perspectives, vol. 30, no. 2, pp. 79-82, 2009.

[17] B. Sinclair and F. Ferguson, "Integrating simulated teaching/learning strategies in undergraduate nursing education," International Journal of Nursing Education Scholarship, vol. 6, no. 1, pp. 1-11, 2009.

[18] L. Birch, N. Jones, P. M. Doyle et al., "Obstetric skills drills: evaluation of teaching methods," Nurse Education Today, vol. 27, no. 8, pp. 915-922, 2007.

[19] C. J. Gordon and T. Buckley, "The effect of high-fidelity simulation training on medical-surgical graduate nurses' perceived ability to respond to patient clinical emergencies," Journal of Continuing Education in Nursing, vol. 40, no. 11, pp. 491-498, 2009.

[20] A. Bandura, "Self-efficacy: toward a unifying theory of behavioral change," Psychological Review, vol. 84, no. 2, pp. 191-215, 1977.

[21] A. W. Chickering and Z. F. Gamson, "Seven principles of good practice in undergraduate education," AAHE Bulletin, vol. 39, no. 7, pp. 5-10, 1987.

[22] National League for Nursing, Student Satisfaction and SelfConfidence in Learning Scale, National League for Nursing, New York, NY, USA, 2007.

[23] P. Jeffries and K. Rogers, "Theoretical framework for simulation design," in Simulation in Nursing Education: From Conceptualization to Evaluation, I. P. R. Jeffries, Ed., pp. 21-33, National League for Nursing, New York, NY, USA, 2007.

[24] M. N. Bremner, K. Aduddell, D. N. Bennett, and J. B. VanGeest, "The use of human patient simulators: best practices with novice nursing students," Nurse Educator, vol. 31, no. 4, pp. 170-174, 2006.

[25] N. Allcock, "Teaching the skills of assessment through the use of an experiential workshop," Nurse Education Today, vol. 12, no. 4, pp. 287-292, 1992.

[26] C. Coyer, G. Gascoin, L. Sentilhes, C. Savagner, J. Berton, and F. Beringue, "Evaluation of the impact and efficiency of high-fidelity simulation for neonatal resuscitation in midwifery education," Archives de Pédiatrie, vol. 21, no. 9, pp. 968-975, 2014.

[27] R. A. Parker, J. A. McNeill, L. W. Pelayo, K. A. Goei, J. Howard, and M. D. Gunter, "Pediatric clinical simulation: a pilot project," Journal of Nursing Education, vol. 50, no. 2, pp. 105-111, 2011. 
[28] D. Goldenberg, M.-A. Andrusyszyn, and C. Iwasiw, "The effect of classroom simulation on nursing students' self-efficacy related to health teaching," Journal of Nursing Education, vol. 44, no. 7, pp. 310-314, 2005.

[29] F. Ghodsbin and M. Shafakhah, "Facilitating and preventing factors in learning clinical skills from the viewpoints of the third year students of Fatemeh School of Nursing and Midwifery," Iranian Journal of Medical Education, vol. 7, no. 2, pp. 343-352, 2008.

[30] C. Thomas and E. Mackey, "Influence of a clinical simulation elective on baccalaureate nursing student clinical confidence," Journal of Nursing Education, vol. 51, no. 4, pp. 236-239, 2012.

[31] M. A. Kaddoura, "New graduate nurses' perceptions of the effects of clinical simulation on their critical thinking, learning, and confidence," Journal of Continuing Education in Nursing, vol. 41, no. 11, pp. 506-516, 2010.

[32] J. Tiffen, N. Graf, and S. Corbridge, "Effectiveness of a lowfidelity simulation experience in building confidence among advanced practice nursing graduate students," Clinical Simulation in Nursing, vol. 5, no. 3, pp. el13-el17, 2009.

[33] D. Brown and C. Chronister, "The effect of simulation learning on critical thinking and self-confidence when incorporated into an electrocardiogram nursing course," Clinical Simulation in Nursing, vol. 5, no. 1, pp. 45-52, 2009. 

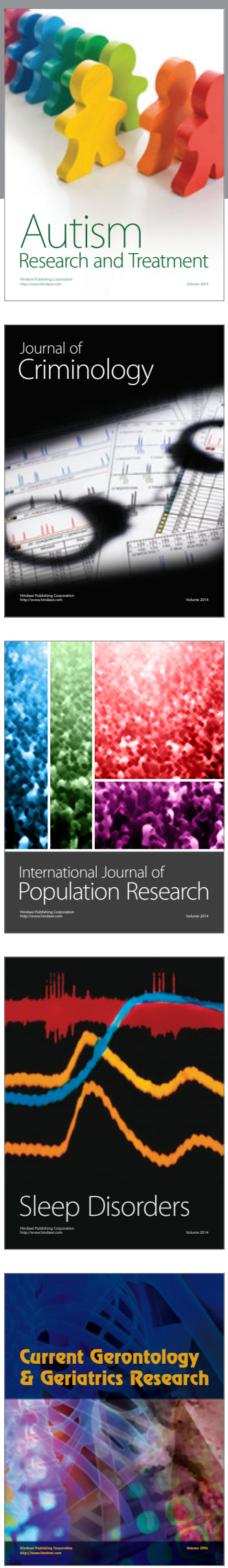
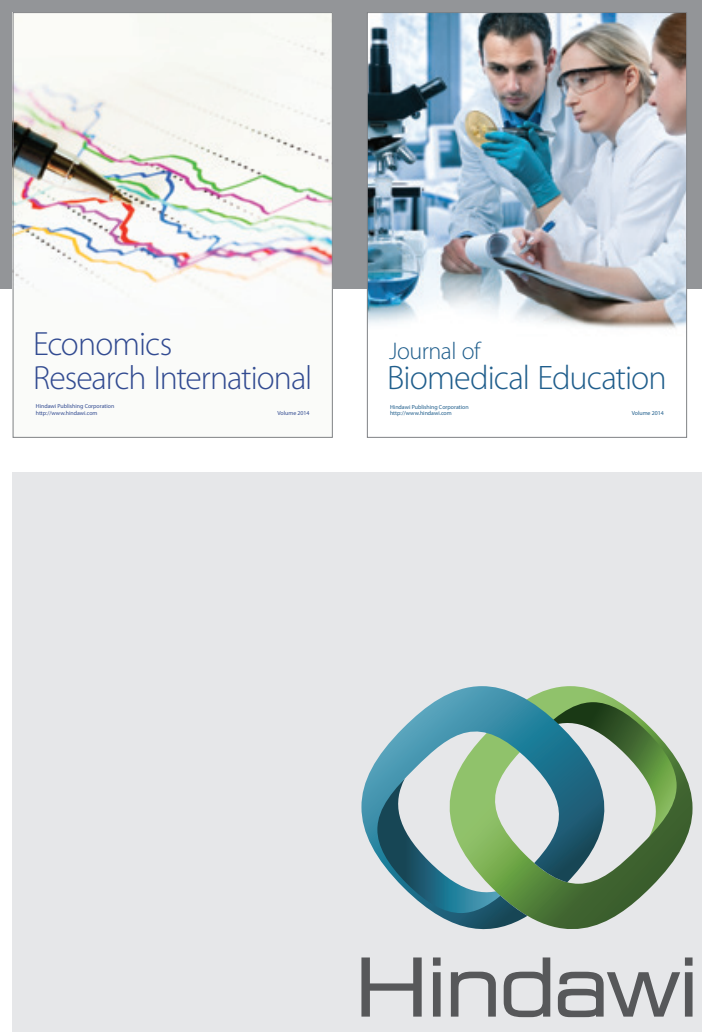

Submit your manuscripts at

http://www.hindawi.com
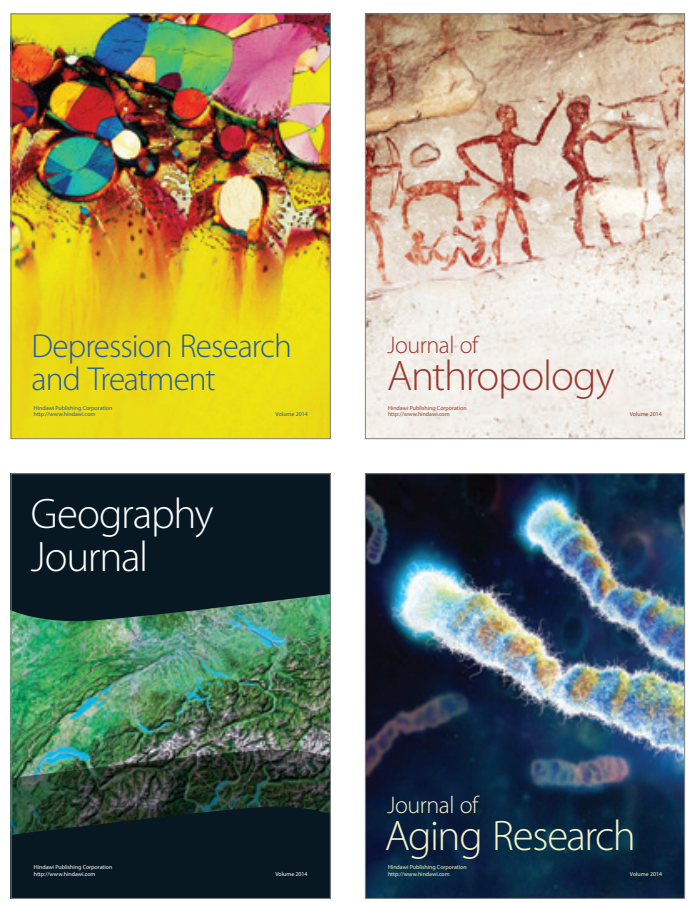
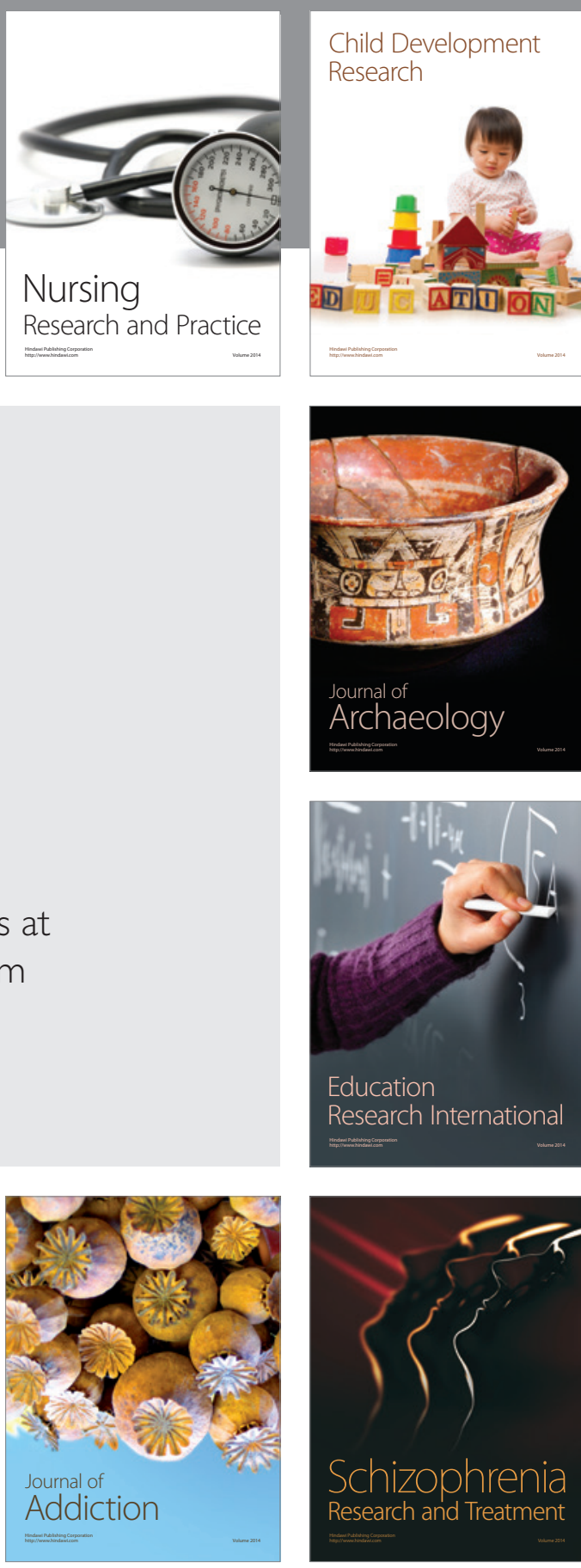

(D)
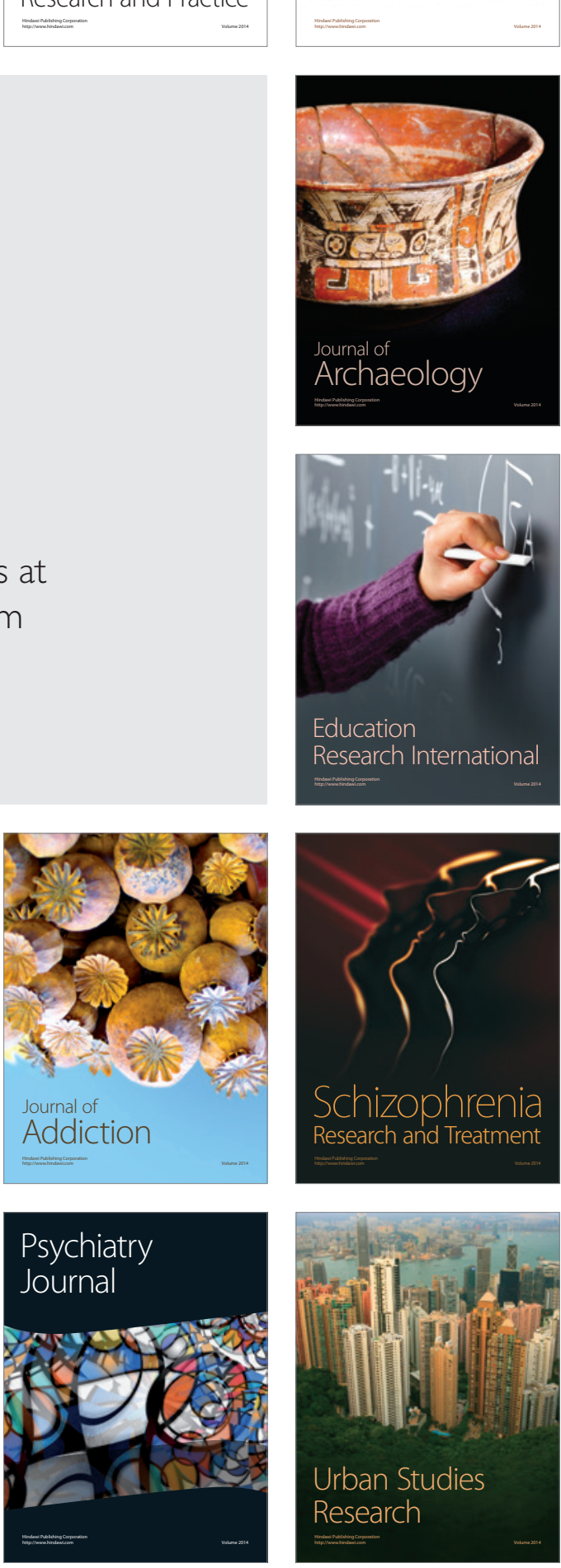